\title{
Project Accelerate: Increasing STEM Opportunities for Underserved High School Students
}

\author{
Andrew G. Duffy and Mark D. Greenman \\ Department of Physics, Boston University, 590 Commonwealth Avenue, Boston, MA, 02215, USA
}

\begin{abstract}
Project Accelerate is a NSF-funded project aimed at helping prepare underserved high school students for the AP Physics 1 exam. The students attend schools that do not offer AP Physics 1. All Project Accelerate students are enrolled in a scaffolded small private online course (SPOC) that takes them through the physics material in an interactive way. A significant fraction of the students, including all those in the Boston area, also attend weekly 2.5 -hour sessions on campus to do hands-on lab activities and recitation exercises. These sessions are led by undergraduate students who have pedagogical training. Our data indicate that Project Accelerate participants do at least as well on the AP Physics exam as similar students who take an AP Physics 1 through a traditional classroom-based course. One of the main goals of Project Accelerate is to give underserved students access to a rigorous science course, helping these students to build a solid foundation for a possible undergraduate degree in STEM. We also present evidence that successfully completing Project Accelerate makes students more likely to pursue further opportunities in STEM.
\end{abstract}

\section{INTRODUCTION}

Physics has significant problems in regards to equity and diversity - these are also major issues in high school education across the United States [1]. Students in suburban schools have greater access to high-quality STEM education than do rural and urban students. Access to Advanced Placement (AP) courses follows this pattern, and there is evidence that not having such access is a barrier between underserved students and a future career in STEM. While under-represented youth make up more than $50 \%$ of today's high school population, African-American/Black and Hispanic/Latino youth each comprise only $7 \%$ of STEM graduates and $6-7 \%$ of the STEM workforce [2]. In a global economy increasingly dependent on STEM competencies, failing to prepare all students to enter STEM fields undermines economic competitiveness and falls short of providing all children opportunities for life success. For instance, only $25 \%$ of underserved STEM students met the ACT College Readiness Benchmark in science compared to $59 \%$ of students who are not underserved. These data indicate that a program to increase academic readiness could have success in increasing participation in STEM baccalaureate and career pathways [3].

Recent reports indicate schools with predominantly lowincome students, both rural and urban, lag in AP offerings by a 2:1 margin, and underrepresented groups lag in taking these courses, even when offered, by a factor of 2-4 compared to whites and Asians $[4,5]$. There is also evidence that in schools that do offer AP programs, there is a large gap in participation between low- and high-income students, regardless of race. Economically disadvantaged and underrepresented students share an equal interest in STEM as non-underserved students, but are too often lacking the opportunity to access these gateway courses to success in physical science college programs and STEM careers [3].
The Boston Public School (BPS) system is an example of the national problem. BPS is a typical urban system, with 34 high schools serving 51,000 students. Of these 34 high schools, in 2015-16 only four offered AP Physics 1, the curriculum supported by Project Accelerate. Removing the Project Accelerate students from the district totals, only 151 BPS students took the AP Physics 1 exam in 2016, and just $8 \%$ of these students earned a 3 or better. This is less than one-fifth of the overall Massachusetts success rate of $43 \%$. BPS, with demographics of $75 \%$ black or Hispanic and nearly $100 \%$ on free or reduced lunch programs, shows AP Physics 1 scores similar to the national AP Physics 1 scores for underrepresented minorities. The success rate (score of 3 or higher) nationally for black and Hispanic students taking the AP Physics 1 exam in 2016 was $16 \%$. Compared to BPS, Massachusetts in general has a much higher percentage of white students, with a significantly lower percentage on free or reduced lunch programs. The demographics of Project Accelerate participants are representative of the populations they are drawn from.

This paper details a project that helps to address the issues of equity and diversity. Our hope is that the project can serve as a model to be adopted both in physics and in other STEM fields across the nation. Project Accelerate is a scalable solution removing an important education barrier keeping many low-income students and under-represented students from succeeding in STEM fields.

\section{RESEARCH QUESTIONS}

Project Accelerate has several research questions. The two questions we focus on in this paper are:

(1) How do students who do the blended or online only versions of Project Accelerate do on the AP Physics 1 exam, in comparison to similar students who take AP Physics 1 in a traditional classroom?

(2) Does completing Project Accelerate have any impact on the students' future experiences in STEM? 


\section{DESCRIPTION OF PROJECT ACCELERATE}

Project Accelerate, funded through the National Science Foundation's DRK-12 program, is a partnership program between Boston University, West Virginia University, and high schools bringing a College Board accredited AP Physics 1 course to schools not offering this opportunity. Economically disadvantaged high school students in many urban, rural, and small suburban communities don't have access to rigorous physics courses. Lacking such an opportunity, these demographic groups are hard pressed to compete in Science, Technology, Engineering and Mathematics (STEM) fields and academic programs with their peers from more affluent communities.

Project Accelerate combines supportive infrastructures from the students' home school with a private edX online instructional tool containing scaffolding specific to the target high school population, multiple assessment tools, simulations, and a suite of virtual explorations emphasizing science process practices. Partner high schools provide time during the school day, equivalent to other major courses, for the student to work in the online instructional tool. A professional member of the high school staff is appointed as a liaison to facilitate communication between the local school and Project Accelerate staff. The course is recorded on the student's high school transcript and report card, and grades and midterm performance reports are provided by Project Accelerate staff. All students in the program are required to take the AP Physics 1 exam and Project Accelerate reimburses AP registration fees for students on free/reduced lunch or equivalent programs.

The online course that serves as the backbone of Project Accelerate is based on a Massive Open Online Course (MOOC) on edX, called Preparing for the AP Physics 1 Exam. That MOOC was created by the two authors of this paper, along with four Boston-area high school physics teachers. The MOOC has been offered four times, running annually on a September - May timetable. By design, the MOOC does not emphasize learning through watching videos. Instead, students are expected to interact with the material, working with on-line labs and a large number of simulations and completing a significant number of selfassessments.

Mark Greenman then took the MOOC, copied it to edX edge, the edX platform for private courses, and transformed it to better serve the needs of underserved high school physics students. Key additions to the small private online course (SPOC), compared to the MOOC, focus on adding structure, expressly to benefit underserved students. These include:

- $\quad$ significantly more scaffolding of the material;

- regular due dates, to make sure that the students stay on track for completion;

- $\quad$ having regular timed AP-style tests, to familiarize the students with the level and rigor required of the AP Physics 1 exam;
- a detailed collection of more than two dozen handson lab activities, so distant students can complete these at their own schools.

In all, the SPOC has 26 graded virtual explorations; 28 graded homework assignments; 26 graded quizzes; and 8 AP-style timed tests. The students work on these between September and April, preparing themselves for the AP Physics 1 exam in early May.

Students in Project Accelerate are generally in one of two groups:

1. Commuting students - students who are within commuting distance of Boston University (or, when the project expands, another regional hub). In addition to learning physics through the online course, the commuting students attend weekly small-group sessions that are led by trained physics major undergraduates. During these sessions, the students complete hands-on laboratory experiments as well as work together on recitation packets that focus on conceptual understanding. Group work is emphasized here - it is important that these students feel that they're not alone in the program.

2. Distant students - in 2017, this group consisted of students in western Massachusetts, New York City, and West Virginia, through our partnership with Gay Stewart at West Virginia University. These students primarily learned the content through the online course, but there were also several options available for them to complete a similar lab experience, such as conducting lab experiments at their home school. Most of our distant partner schools provided a hands-on laboratory experience to complement the online instructional tool.

The structure of Project Accelerate is shown as a schematic view in Figure 1. Each partner high school has a staff member (the high school liaison) who facilitates communication between the school and the university. Note that high school liaisons do not provide physics instruction that is done via the course. Students are vetted by the high school for acceptance into the program, and grades are reported back from the program to the high school liaison. Coordinating various high schools are the university liaisons. These are generally current or retired physics teachers who monitor the discussion forum within the online course, responding to questions there, and also providing the grades back to the high school liaisons. The university liaisons are accountable to senior Project Accelerate staff.

The vetting process for students is quite rigorous. First, the students should have expressed a strong interest in doing the course. Second, they have to have demonstrated ability in math. Third, they need to have demonstrated an ability to work independently. These abilities are assessed by the individual schools - in our experience, they are critical to the success of the students. To participate in Project Accelerate, 


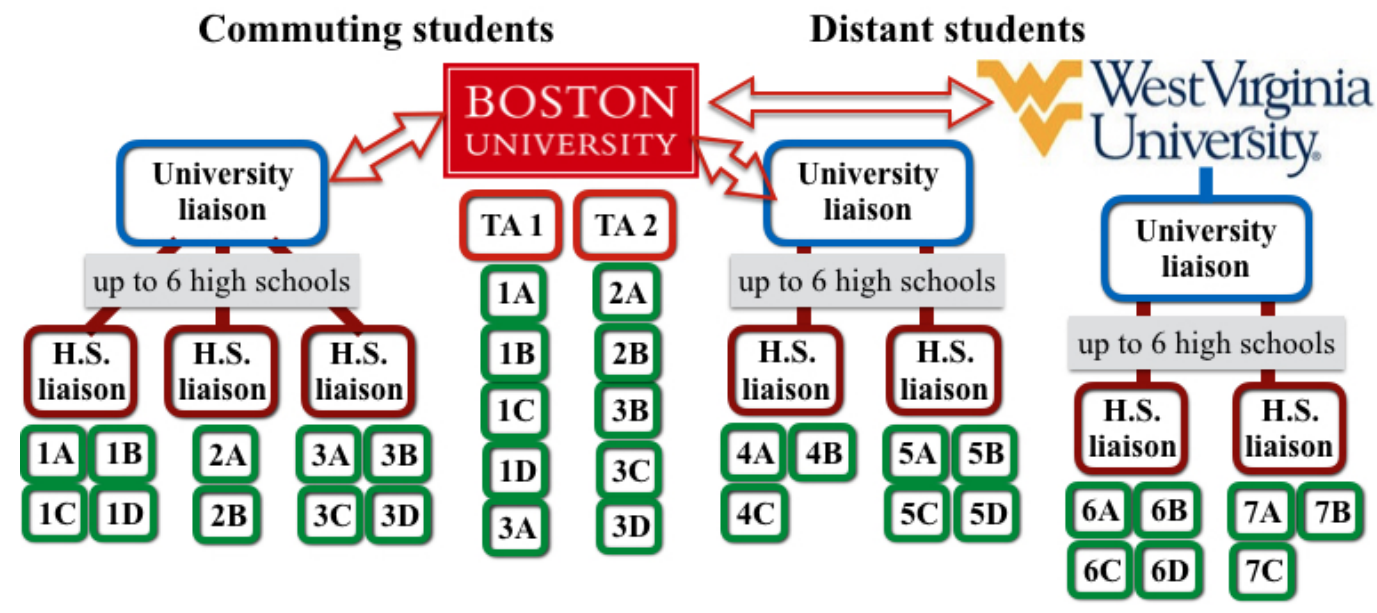

Figure 1. A schematic diagram of the Project Accelerate structure. The diagram shows ten commuting students from three schools, who also attend weekly small-group 2.5-hour lab/recitation sessions at Boston University. The figure also shows 14 distant students, which could represent 7 from two schools in western Massachusetts and 7 more from two schools in West Virginia, working with our partner institution, West Virginia University. Again, this is a schematic view. In 2017-18, there were many more high schools and students involved in Project Accelerate, with 25 commuting students and 33 distant students. The TAs are undergraduate students who receive the same pedagogical training as do Learning Assistants at Boston University.

the schools cannot offer an AP Physics course themselves, and each school generally enrolls between two and eight students in the program. As mentioned above, the demographics of Project Accelerate participants mirror the populations they are drawn from. Thus, our distant students are primarily white, and our commuting students are primarily black and Hispanic.

To get them off to a good start, the students actually enroll in the course during the spring/summer, completing precourse assessment instruments and exercises so they become familiar with the edX edge platform. With everyone enrolled and in the program as of the start of September, the course can open smoothly, with any login issues having already been dealt with.

Between September and April, the students complete the 16 modules of the course at a steady pace, with specific due dates that enable the course staff to report student grades to the high school liaisons. Students are encouraged to post questions in the online discussion forum, and to participate in discussions within the forum. At regular intervals, the students complete mock AP-style tests. Finally, in May all students are required to take the AP Physics 1 exam.

Figure 2 shows the Project Accelerate theory of change. Our hypothesis is that successfully completing the AP Physics 1 program will provide these students a solid foundation for future success in STEM. Note that the theory of change also shows the AP Physics 2 exam - we are making good progress in building an online course for AP Physics 2, with a plan to offer Project Accelerate students who successfully complete AP Physics 1 a chance for a second rigorous STEM course while they are in high school.

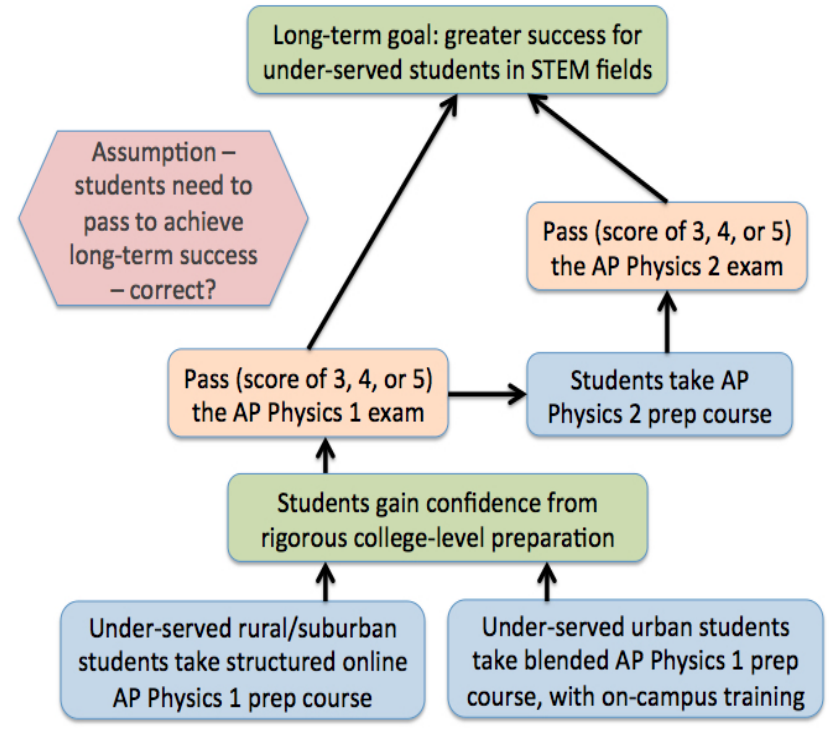

Figure 2. The figure illustrates the theory of change that Project Accelerate is based on, along with one of the underlying assumptions. Our long-term goal is that under-served and under-represented students achieve greater success in STEM. Students are helped to reach this goal by either taking one or two years worth of AP Physics preparation through Project Accelerate.

\section{RESULTS}

Project Accelerate ran as a pilot for 2015-16 and 201617. 2017-18 was the first year of three years of funding from the National Science Foundation. The data on AP scores we 
report in Table 1 is for all three years. Table 2 shows comparison groups.

\begin{tabular}{|c|c|c|}
\hline & Commuting & Distant \\
\hline Enrolled & 67 students & 72 students \\
\hline Completed & 45 students & 58 students \\
\hline AP 3, 4, or 5 & 5 students & 23 students \\
\hline \% AP 3, 4, or 5 & $11 \%$ & $40 \%$ \\
\hline
\end{tabular}

Table 1: Summary of results from the two pilot years of Project Accelerate $(2015-16+2016-17)$ plus the first year (2017-18) of NSF funding (combined).

\begin{tabular}{|c|c|c|}
\hline Group & \# of students & \% AP 3, 4, or 5 \\
\hline Nation (white) & 83,702 & $46 \%$ \\
\hline $\begin{array}{c}\text { Nation } \\
\text { (black/Hispanic) }\end{array}$ & 39,402 & $16 \%$ \\
\hline $\begin{array}{c}\text { MA public (non- } \\
\text { BPS) }\end{array}$ & 3398 & $43 \%$ \\
\hline $\begin{array}{c}\text { Boston Public } \\
\text { Schools (BPS) }\end{array}$ & 151 & $8 \%$ \\
\hline
\end{tabular}

Table 2: Results from 2016 for comparison groups on the AP Physics 1 exam (other years are similar). Note the huge disparity between white students vs. black and Hispanic students, reflected in the MA results for non-BPS and BPS.

The results above show that students in Project Accelerate perform as well as their peer groups enrolled in AP Physics 1 in traditional classroom-based courses on the College Board AP Physics 1 exam. Our distant students had a success rate of $40 \%$ compared to MA public schools $43 \%$, and our commuting students from BPS had a success rate of $11 \%$ compared to BPS students' $8 \%$. Note that the AP Physics 1 exam is difficult - the overall percentage of 3's, 4's, and 5's on the 2018 exam was slightly under $40 \%$, which is fairly typical.

Our distant students do much better than our commuting students, which we ascribe to the distant students having a stronger foundation than students who have come through the Boston Public School system. Like many urban school districts in the US, the BPS on average is lower performing than non-urban school districts.

Studies have shown that students who score 3 or higher on AP exams have greater success in college than students who did not do an AP course, but students who received scores lower than 3 do not perform noticeably better $[5,6]$. This indicates how important quality curriculum and appropriate scaffolding are to student success [7].
We also investigated whether completing Project Accelerate made students more likely to participate in future STEM activities. In the three years of the program, $52(52 \%)$ of the 99 participants who completed the end of course survey indicated-that they were more likely to pursue a STEM program in college now that they had their Project Accelerate experience. Only four students said they were less likely to do this. In addition, 17 of 43 (40\%) commuting students applied to summer STEM programs, with 11 of 17 (65\%) who applied to summer STEM programs indicating that their participation in Project Accelerate was important in their decision to apply.

\section{CONCLUSIONS AND FUTURE PLANS}

Our study indicates that either a blended program that combines a rigorous online course with on-campus lab and recitation sessions, or just learning online through the scaffolded course, designed especially for underserved students, produces outcomes on the AP Physics 1 exam that are similar to those of comparable students who have had more traditional classes at their schools. Because of this, we feel confident in saying that the Project Accelerate model could be a way to address the equity issue of underserved high school students not having the same access to highquality STEM education as more advantaged students.

Project Accelerate has grown from 6 partner high schools in 2015-16 to 19 high school partners for 2018-2019. During this same period, the project has moved from being based in Massachusetts to also having a partner high school in Manhattan, NY, and a significant presence in West Virginia with six partner schools. Moving forward, we intend to recruit at least one more university partner, and do further evaluation to provide evidence for whether or not Project Accelerate can serve as a national model to support underserved students in physics across the nation, and/or to expand the program to other STEM disciplines.

\section{ACKNOWLEDGEMENTS}

This material is based upon work supported by the National Science Foundation under Grant No. DRL 1720914. Any opinions, findings, and conclusions or recommendations expressed in this material are those of the author(s) and do not necessarily reflect the views of the NSF. The two pilot years of the program were funded by the Digital Learning Initiative at Boston University. We would also like to acknowledge the helpful comments of two reviewers.
[1] M. Rifkin, Phys. Teach. 54, 72 (2016).

[2] L.C Landivar, US Census Report (2013), https://www.census.gov/prod/2013pubs/acs-24.pdf [3] The Condition of STEM 2014 (ACT, 2014), https://www.act.org/content/dam/act/unsecured/documents/ National-STEMReport-2014.pdf
[4] P. Handwerk et al., Educational Testing Service (2008).

[5] K. Klopfenstein and M.K. Thomas, American Economic Association Annual Meeting Papers, (2005).

[6] P. M. Sadler and R. H. Tai, Sci. Educ. 16(2), 1-19 (2007).

[7] K. Klopfenstein, Am. Secondary Educ., 39-43 (2003). 